\title{
Special Issue: Design, Branding and Marketing: Experience and Value Creation in Design, Branding, Marketing, Corporate Reputation and Identity
}

๑) Springer Nature Limited 2020

\section{Guest editors}

Katelijn Quartier, Hasselt University, Belgium Ann Petermans, Hasselt University, Belgium Charles Dennis, Middlesex University, UK T C Melewar, Middlesex University, UK

This Special Issue explores aspects of theory and practice that cross perceived boundaries between marketing and design. It aims to include academic work of merit that spans the areas of branding, corporate reputation and identity, promotion, product development, retail design, online and/or multimedia consumer engagement. This Special Issue aims particularly to focus on aspects of the creative process, exploring interdisciplinary connections between research, practice and teaching.

Some key questions which we aim to explore in this Special Issue are:

- How can we enhance the possibility of bringing design, branding, marketing, reputation and identity research together to generate innovative ideas for practice, so 'better' experiences and more value are triggered or created?

- What does 'value' mean in today's economy and how does this reflect on research in design, branding, marketing, reputation and identity?

- How do we teach students about the creation of experiential value?

- To what extent do experiences play in satisfying today's customers?

Conceptual and empirical papers that address the proposed themes of the special issue are welcome. Papers may address issues including, but not necessarily limited to:
- creativity, brand management, identity, reputation and co-creation

- collaborative fusion and/or co-design between marketers and designers, or designers and customers, or marketers and customers

- sensory aspects of design, reputation and identity

- the creative process in retail and service marketing and design

- adding or creating value in marketing, retail and / or marketing communications

- interior and spatial design developments

- organizational identity and image in services and retail environments

- e-commerce and online marketing and reputation building

- creativity and design for interaction

- co-creative processes

- experience marketing, experiential design and design innovations

- retail design innovation and corporate identity

- (visual) research methodology developments

- creative design practice-based research: implications for marketing, services, research and teaching

All manuscripts should follow the general author guidelines for Corporate Reputation Review. Manuscripts should not have been previously published or be under consideration by other journals. Please submit your paper electronically.

Submission deadline: 30th April 2021 